\title{
Leishmania amazonensis: Characterization of an ecto-phosphatase activity
}

\author{
Elmo Eduardo de Almeida-Amaral a , Rodrigo Belmont-Firpo a \\ Marcos André Vannier-Santos ${ }^{b}$, José Roberto Meyer-Fernandes ${ }^{a, *}$ \\ a Instituto de Bioquímica Médica, Universidade Federal do Rio de Janeiro-UFRJ, CCS, Bloco H sala H2-013, Cidade Universitária, Ilha do Fundão, \\ 21941-590 Rio de Janeiro, RJ, Brazil \\ ${ }^{\mathrm{b}}$ Centro de Pesquisas Gonçalo Moniz, Fundação Oswaldo Cruz-FIOCRUZ, Rua Waldemar Falcão 121, Brotas, 40295-001 Salvador, BA, Brazil
}

Received 27 December 2005; received in revised form 26 April 2006; accepted 29 April 2006

Available online 30 June 2006

\begin{abstract}
We have characterized a phosphatase activity present on the external surface of Leishmania amazonensis, using intact living parasites. This enzyme hydrolyzes the substrate $p$-nitrophenylphosphate $\left(p\right.$-NPP) at the rate of $25.70 \pm 1.17 \mathrm{nmol} \mathrm{Pi} \times \mathrm{h}^{-1} \times 10^{-7}$ cells. The dependence on $p$-NPP concentration shows a normal Michaelis-Menten kinetics for this ecto-phosphatase activity present a $V_{\text {max }}$ of $31.93 \pm 3.04 \mathrm{nmol} \mathrm{Pi} \times \mathrm{h}^{-1} \times 10^{-7}$ cells and apparent $K_{\mathrm{m}}$ of $1.78 \pm 0.32 \mathrm{mM}$. Inorganic phosphate inhibited the ecto-phoshatase activity in a dose-dependent manner with the $K_{\mathrm{i}}$ value of $2.60 \mathrm{mM}$. Experiments using classical inhibitor of acid phosphatase, such as ammonium molybdate, as well as inhibitors of phosphotyrosine phosphatase, such as sodium orthovanadate and [potassiumbisperoxo(1,10-phenanthroline)oxovanadate(V)] (bpV-PHEN), inhibited the ecto-phosphatase activity, with the $K_{\mathrm{i}}$ values of $0.33 \mu \mathrm{M}, 0.36 \mu \mathrm{M}$ and $0.25 \mu \mathrm{M}$, respectively. Zinc chloride, another classical phosphotyrosine phosphatase inhibitor, also inhibited the ecto-phosphatase activity in a dose-dependent manner with $K_{\mathrm{i}} 2.62 \mathrm{mM}$. Zinc inhibition was reversed by incubation with reduced glutathione (GSH) and cysteine, but not serine, showing that cysteine residues are important for enzymatic activity. Promastigote growth in a medium supplemented with $1 \mathrm{mM}$ sodium orthovanadate was completely inhibited as compared to the control medium. Taken together, these results suggest that $L$. amazonensis express a phosphohydrolase ectoenzyme with phosphotyrosine phosphatase activity.
\end{abstract}

(c) 2006 Elsevier Inc. All rights reserved.

Index Descriptors and Abbreviations: Leishmania amazonensis; Ecto-phosphatase activity; Phosphotyrosine phosphatase

\section{Introduction}

Leishmaniasis is a parasitic disease caused by protozoa of the genus Leishmania affecting more than 12 million people worldwide (Desjeux, 2004). These parasites exist as motile flagellate promastigotes that live in the alimentary tract of blood-sucking sand flies and as nonflagellate intracellular amastigote mostly within the macrophages of mammalian hosts (Vannier-Santos et al., 2002). The severity of the disease produced by several Leishmania species varies widely, ranging from cutaneous and/or mucosal to

\footnotetext{
* Corresponding author. Fax: +55212270 8647.

E-mail address: meyer@bioqmed.ufrj.br (J.R. Meyer-Fernandes).
}

visceral infection. Leishmania amazonensis, formerly described in the Amazon region, also occurs in many parts of Brazil and is the ethiological agent of cutaneous lesions or diffuse cutaneous (Grimaldi and Tesh, 1993), but it is noteworthy that $L$. amazonensis may cause the complete clinical spectrum of leishmaniasis, including the diffuse cutaneous and the visceral infection (Barral et al., 1991).

The plasma membrane of cells may display enzymes whose active sites face the external medium rather than the cytoplasm. The activities of these enzymes, referred to as ectoenzymes, can be measured by assaying intact cells (Fernandes et al., 2003; Lemos et al., 2002; Jesus et al., 2002; Meyer-Fernandes et al., 1997). Membrane-bound acid phosphatase activities have been characterized in some species of the family Trypanosomatidae, such as Trypanosoma 
spp. (Bakarala et al., 2000; Fernandes et al., 1997; Furuya et al., 1998; Meyer-Fernandes et al., 1999), Herpetomonas muscarum muscarum (Dutra et al., 1998), Leishmania donovani (Glew et al., 1982; Remaley et al., 1985) and in Leishmania mexicana, where this enzyme was purified (Menz et al., 1991; Wiese et al., 1996).

Protein phosphorylation comprises a major mechanism in the control of biological phenomena in most organisms. Phosphorylation-dephosphorylation of serine, threonine, and tyrosine residues triggers conformational changes that modulate protein biological properties (Hunter, 1995). The signaling regulation of the stimulus-response coupling during differentiation and proliferation is largely mediated by protein phosphorylation in eukaryotes (Hunter, 1995), including Trypanosomes (Parsons et al., 1993). In various tissues and cells, the presence of phosphotyrosyl protein phosphatases, which are also active toward low molecular weight, nonprotein phosphoesters such as alkyl and aryl phosphates, including $p$-nitrophenylphosphate ( $p$-NPP), has been described (Lau et al., 1989). The presence of protein tyrosine phosphatase activities in $L$. donovani (Cool and Blum, 1993), Trypanosoma brucei (Bakarala et al., 2000; Fernandes et al., 2003) and Trypanosoma cruzi (Furuya et al., 1998; Meyer-Fernandes et al., 1999) has been demonstrated. Although the physiological role of the membrane-bound acid phosphatases has not been well established, they are supposed to be involved with nutrition (Gottlieb and Dwyer, 1981) escape (Gottlieb and Dwyer, 1981; Martiny et al., 1999; Remaley et al., 1985; Remaley et al., 1985; Saha et al., 1985), virulence (Furuya et al., 1998; Katakura and Kobayashi, 1988; Singla et al., 1992;), and cell differentiation (Meyer-Fernandes et al., 1999).

Recently, it has been shown the presence of a membranebound protein tyrosine phosphatase on the surface of Leishmania major (Aguirre-García et al., 2006). Here, we have characterized an ecto-phosphatase activity in L. amazonensis and demonstrated its modulation by compounds that can modify SH groups and specific inhibitors of protein tyrosine phosphatase $\left(\mathrm{ZnCl}_{2}\right.$, sodium orthovanadate, and bpV-PHEN). We also demonstrated the inhibitory effect of sodium orthovanadate in the cell proliferation.

\section{Materials and methods}

\subsection{Microorganisms}

The MHOM/BR/75/Josefa strain of L. amazonensis was used throughout this study. It was isolated from a human case of diffuse cutaneous leishmaniasis in Brazil and provided by Dr. Cuba-Cuba (Universidade de Brasília, Brazil) and has been maintained in our laboratory since then in axenic culture. Promastigotes were cultured in Warren's medium (Warren, 1960) supplemented with 10\% heat-inactivated fetal bovine serum at $22^{\circ} \mathrm{C}$. Parasites were harvested at the stationary phase of growth by centrifugation, washed twice and kept in $116 \mathrm{mM} \mathrm{NaCl}, 5.4 \mathrm{mM} \mathrm{KCl}$, $5.5 \mathrm{mM}$ D-glucose, and $50.0 \mathrm{mM}$ Hepes-Tris buffer, $\mathrm{pH}$ 7.2.
Cellular viability was assessed before and after incubations, by motility and by trypan blue dye exclusion (Dutra et al., 1998). The viability was not affected under the conditions employed here.

\subsection{Phosphatase measurements}

The phosphatase activity was measured by the rate of $p$ nitrophenol ( $p$-NP, $p$-NPP hydrolysis product), production. Intact cells were incubated for $1 \mathrm{~h}$ at $30^{\circ} \mathrm{C}$ in $0.5 \mathrm{ml}$ of reaction mixture containing $116.0 \mathrm{mM} \mathrm{NaCl}, 5.4 \mathrm{mM} \mathrm{KCl}$, $5.5 \mathrm{mM}$ glucose, $50.0 \mathrm{mM}$ Hepes-Tris buffer, pH 7.0, $5.0 \mathrm{mM} p$-nitrophenylphosphate ( $p$-NPP) as substrate and $2 \times 10^{7}$ cells ml ${ }^{-1}$. The reaction was initiated by addition of cells and stopped by the addition of $1.0 \mathrm{ml} 1 \mathrm{~N} \mathrm{NaOH}$. Controls, where cells were added after interruption of the reaction, were used as blank. For determining the concentration of released $p$-NP, the tubes were centrifuged at $1500 \mathrm{~g}$ for $15 \mathrm{~min}$ and the supernatants were measured spectrophotometrically at $425 \mathrm{~nm}$, using an extinction coefficient of $14.3 \times 10^{3} \mathrm{M}^{-1} \mathrm{~cm}^{-1}$. We also tested phosphoamino acids as substrates. In this case, the hydrolytic activities were spectrophotometrically analyzed by measuring the released inorganic phosphate from these substrates, under the same condition employed above (Fiske and Subbarow, 1925). The values obtained for $p$-nitrophenylphosphatase activity measured using these methods were exactly the same. The values shown represent average $\pm \mathrm{SE}$ of three independent experiments.

\subsection{Inhibition assays}

Phosphatase activity of intact cells of $L$. amazonensis was analyzed with specific inhibitors of protein tyrosine phosphatase $\left(\mathrm{ZnCl}_{2}\right.$, sodium orthovanadate and $\mathrm{bpV}$ PHEN). We also analyzed the effect of ammonium molybdate (an inhibitor of acid phosphatase) and inorganic phosphate (the natural product of the phophatase activities). The phosphatase activity in the absence of inhibitors $\left(25.70 \pm 1.17 \mathrm{nmol} \mathrm{Pi} \times \mathrm{h}^{-1} \times 10^{-7}\right.$ cells) was taken as $100 \%$.

\subsection{Reagents}

All reagents were purchased from E. Merck (São Paulo, Brazil) or Sigma-Aldrich (Sigma Co. St. Louis, MO). Deionized distilled water from a MilliQ system of resins (Millipore Corp., Bedford, MA) was used in the preparation of all solutions including substrates and inhibitors.

\subsection{Statistical analysis}

The data were analyzed statistically by means of Stundent's $t$-test. $P$ values of 0.05 or less were considered significant. Apparent $K_{\mathrm{m}}$ and $V_{\max }$ values were calculated using a computerized non-linear regression fit of the data to the Michaelis-Menten equation. $K_{\mathrm{i}}$ values for the inhibitors were calculated using a computerized non-linear regression 
program (Sigma Plot 2000-Jandel Scientific Software, 1986-2000, San Diego, CA, USA) of the data.

\section{Results}

The time-course of phosphatase activity present on the external surface of L. amazonensis was linear for at least $1 \mathrm{~h}$ (Fig. 1A). Similarly, in assay to determine the influence of cell density on the ecto-phosphatase activity, it was observed that this activity was directly proportional to the number of cells (Fig. 1B). At pH 7.2, intact cells were able to hydrolyze $p$-NPP at a rate of $25.70 \pm 1.17 \mathrm{nmol}$ $\mathrm{Pi} \times \mathrm{h}^{-1} \times 10^{-7}$ cells. To exclude the possibility that the observed $p$-NPP hydrolyzed was due to secreted soluble enzymes, cells were incubated in the absence of $p$-NPP. Subsequently, the suspension was centrifuged to remove cells and the supernatant was assayed for phosphatase activity. This supernatant failed to show $p$-NPP hydrolysis (data not shown). These data also rules out the possibility that the phosphatase activity here described could be derived from lysed $L$. amazonensis cells.

The dependence on $p$-NPP concentration showed a normal Michaelis-Menten kinetics for this phosphatase activity and values of $V_{\max }$ and apparent $K_{\mathrm{m}}$ for $p$-NPP were $31.93 \pm 3.04 \mathrm{nmol} \mathrm{Pi} \times \mathrm{h}^{-1} \times 10^{-7}$ cells and $1.78 \pm 0.32 \mathrm{mM}$, respectively (Fig. 2). Different phosphatase inhibitors were tested and the results are shown in Fig. 3. The apparent $K_{\mathrm{i}}$ values for ammonium molybdate (Fig. 3A), sodium orthovanadate (Fig. 3B), bpV-PHEN (Fig. 3C), inorganic phosphate (Fig. 3D) and zinc chloride (Fig. 3E) were, respectively, $0.33 \mu \mathrm{M}, 0.36 \mu \mathrm{M}, 0.25 \mu \mathrm{M}, 2.60 \mathrm{mM}$ and $2.62 \mathrm{mM}$. Lineweaver-Burk plot analysis (Table 1) revealed that ammonium molybdate, sodium orthovanadate, $\mathrm{bpV}$ PHEN and inorganic phosphate were competitive inhibitors while zinc chloride was a noncompetitive inhibitor. Living $L$. amazonensis were also able to hydrolyze $P$-tyrosine, $P$-serine and $P$-threonine at a rate of $10.01 \pm 2.31$, $6.58 \pm 1,48$ and $2.30 \pm 0.26 \mathrm{nmol} \mathrm{Pi} \times \mathrm{h}^{-1} \times 10^{-7}$ cells, respectively (Fig. 4). However, as $p$-NPP, only $P$-tyrosine hydrolysis was inhibited by sodium orthovanadate (Fig. 4).

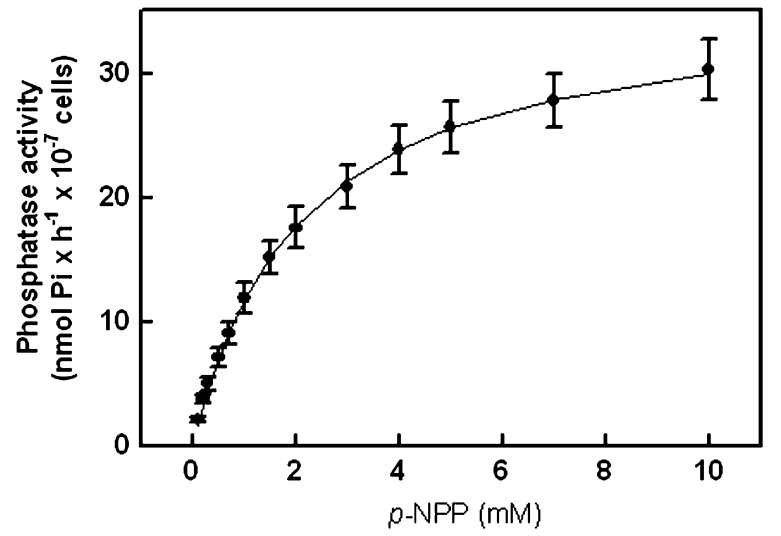

Fig. 2. Dependence of $p$-NPP concentration on the phosphatase activity of L. amazonensis intact cells. Cells were incubated for $1 \mathrm{~h}$ at $30^{\circ} \mathrm{C}$ in the same reaction medium (final volume: $0.5 \mathrm{ml}$ ) described in Fig. 1, with different $p$-NPP concentrations. Curves represent the fit of experimental data by non-linear regression using the Michaelis-Menten equation as described in Section 2. The values represent means \pm standard errors of at least ten independent experiments performed in triplicate.

These data could be indicating that the enzyme responsible for the hydrolysis of $p$-NPP and $P$-tyrosine would be a phoshotyrosine phosphatase, different from that responsible of the $P$-serine and $P$-threonine hydrolysis.

Reduced glutathione (GSH) and cysteine were also tested. Interestingly, both GSH (Fig. 5A) and cysteine (Fig. 5C) were able to revert the inhibition promoted by zinc, in a dose-dependent manner (Fig. 5B and D). However, serine, an amino acid that presents a hydroxyl group instead of a thiol group, did not exert such effect (Fig. 5E). We also examined the effect of $1 \mathrm{mM}$ of sodium orthovanadate in the cell growth of $L$. amazonensis. As shown in Fig. 6, promastigote growth in a medium supplemented with orthovanadate was completely inhibited as compared to control.

\section{Discussion}

The protein tyrosine phosphatase (PTP) contains a signature sequence (I/V) HCXAGXXR(S/T)G, which includes

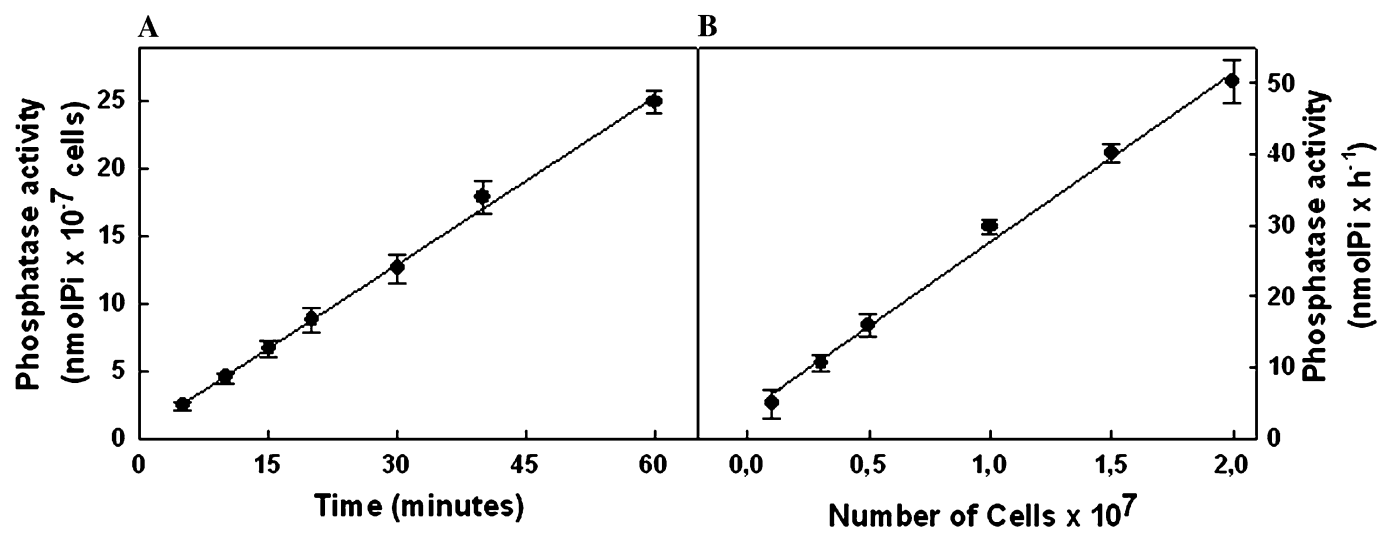

Fig. 1. Time-course (A) cell density-dependence (B) of ecto-phosphatase activity of Leishmania amazonensis. Intact parasite were assayed at $30{ }^{\circ} \mathrm{C}$ in the reaction medium (final volume: $0.5 \mathrm{ml}$ ) containing $116.0 \mathrm{mM} \mathrm{NaCl}, 5.4 \mathrm{mM} \mathrm{KCl}, 5.5 \mathrm{mM}$ glucose, $50.0 \mathrm{mM}$ Hepes-Tris buffer, $\mathrm{pH} 7.0,5.0 \mathrm{mM} p$-NPP. The values represent means \pm standard errors of at least five independent experiments performed in triplicate. 

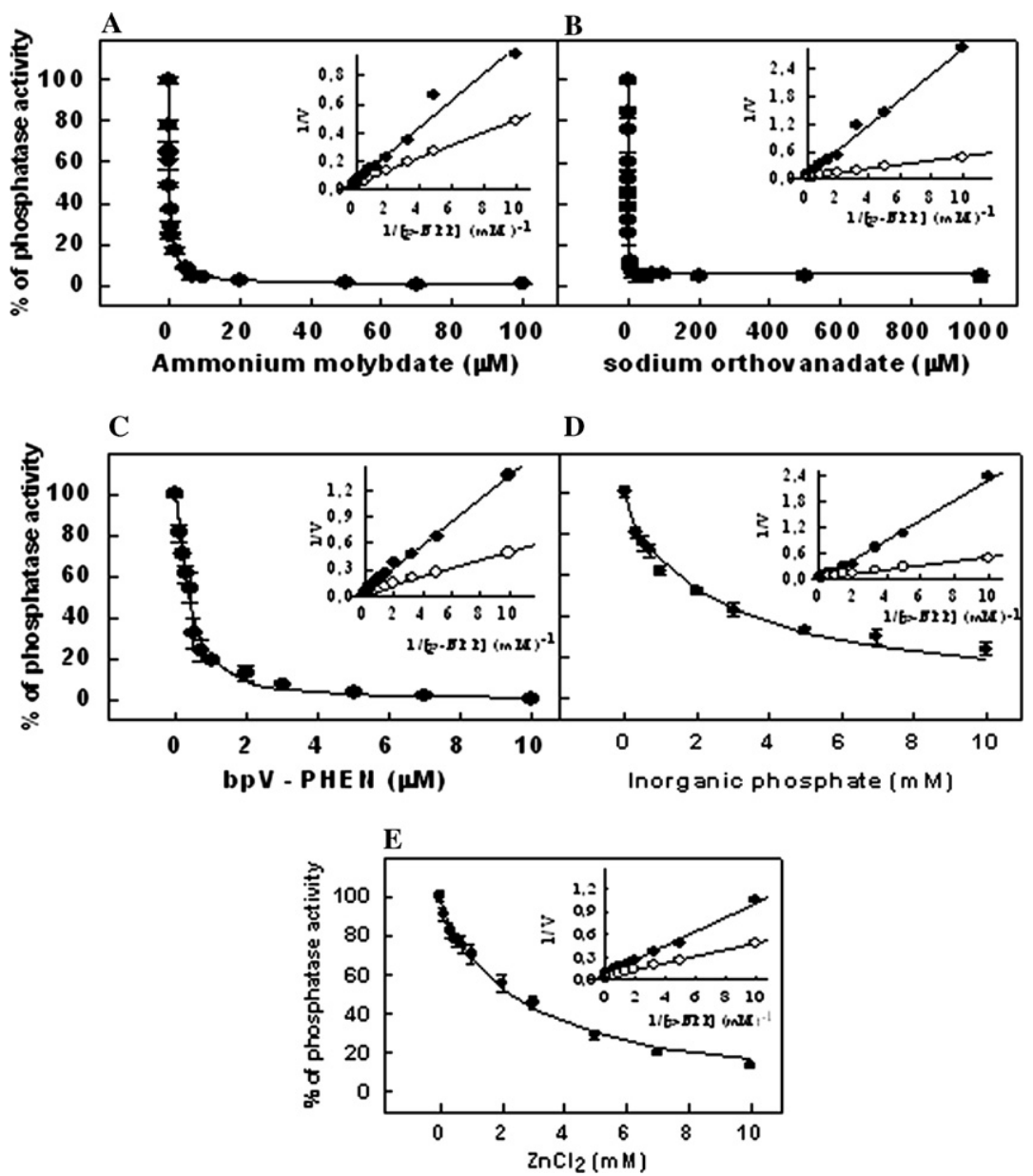

Fig. 3. Effects of different inhibitors on the phosphatase activity of L. amazonensis intact cells. Cells were incubated for $1 \mathrm{~h}$ at $30^{\circ} \mathrm{C}$ in the same reaction medium (final volume: $0.5 \mathrm{ml}$ ) described in Fig. 1 with different concentrations of ammonium molybdate (A), sodium orthovanadate (B), bpV-PHEN (C), inorganic phosphate (D) and $\mathrm{ZnCl}_{2}$ (E) as shown on the abscissa. The values expressed as relative activity represent the mean of at least three independent experiments, which were performed in triplicate. Curves represent the fit of experimental non-linear regression data as described in Section 2. Inset shows Lineweaver-Burk plot of the inhibition of $p$-nitrophenylphosphate hydrolysis by the different inhibitors. Cells were incubated as described above in the absence (open circles) or presence (closed circles) of $0.3 \mu \mathrm{M}$ ammonium molybdate (A), $0.3 \mu \mathrm{M}$ sodium orthovanadate (B), $0.3 \mu \mathrm{M}$ bpV-PHEN (C), $2 \mathrm{mM}$ inorganic phosphate (D) and $3 \mathrm{mM} \mathrm{ZnCl}_{2}(\mathrm{E})$.

Table 1

Kinetic parameters of phosphatase inhibitors on the ecto-phosphatase activity of $L$. amazonensis intact cells

\begin{tabular}{lcl}
\hline Inhibitors & \multicolumn{2}{c}{ Kinetic parameters } \\
\cline { 2 - 3 } & $K_{\mathrm{m}}(\mathrm{mM})$ & $V_{\max }\left(\mathrm{nmol} \mathrm{Pi} \times \mathrm{h} \times 10^{-7}\right.$ cells $)$ \\
\hline Control & $1.78 \pm 0.32$ & $31.93 \pm 3.04$ \\
Inorganic phosphate & $3.92 \pm 0.41^{*}$ & $27.96 \pm 1.36$ \\
Ammonium molybdate & $5.53 \pm 0.75^{*}$ & $34.27 \pm 2.16$ \\
Sodium orthovanadate & $12.37 \pm 2.06^{*}$ & $33.76 \pm 3.76$ \\
bpV-PHEN & $4.57 \pm 0.04^{*}$ & $36.50 \pm 1.19$ \\
$\mathrm{ZnCl}_{2}$ & $1.53 \pm 0.31$ & $15.97 \pm 0.14^{*}$ \\
\hline
\end{tabular}

Cells were incubated as described in Section 2. The values represent means \pm standard errors of at least three independent experiments, performed in triplicate. The Kinetic parameters of apparent $K_{\mathrm{m}}$ and $V_{\max }$ values were calculated using a computerized non-linear regression fit of the data to the Michaelis-Menten equation. ${ }^{*} p<0.05$.

an essential cysteine residue that comprises the active nucleophilic site (Fischer et al., 1991). The cysteine active site is the key for the PTPs catalytic function. The cysteine residue may be regulated by reversible reduction/oxidation involv-

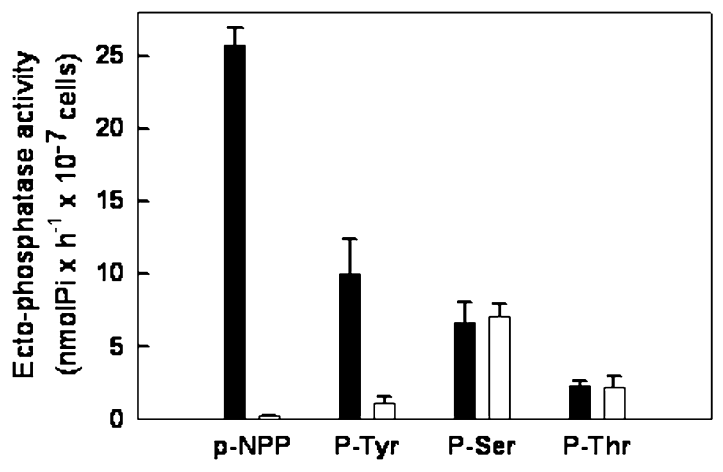

Fig. 4. Substrate specificity in the absence (closed bar) or in the presence of $1 \mathrm{mM}$ sodium orthovanadate (hatched bar). Cells were incubated for $1 \mathrm{~h}$ at $30^{\circ} \mathrm{C}$ in the same reaction medium (final volume: $0.5 \mathrm{ml}$ ) described in Fig. 1 with $5 \mathrm{mM}$ of each substrate $p$-nitrophenylphosphate ( $p$-NPP) or $P$-tyrosine $(P$-Tyr) or $P$-serine $(P$-Ser) or $P$-threonine $(P$-Thr). The data are means \pm standard errors of three determinations with different cells suspensions. 

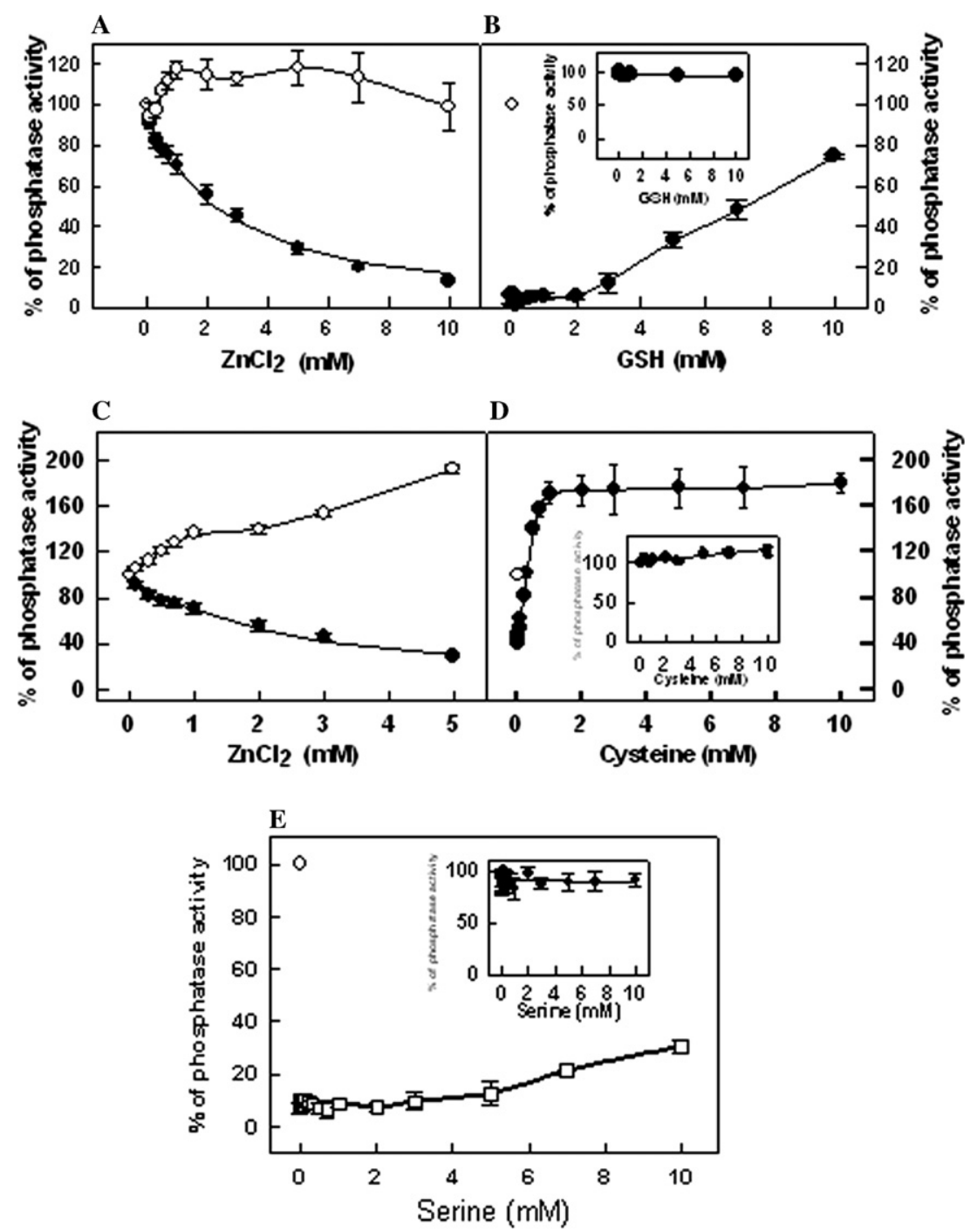

Fig. 5. Effects of reduced glutathione, cysteine and serine in the $\mathrm{ZnCl}_{2}$ inhibition of the phosphatase activity of $L$. amazonensis intact cells. Cells were incubated as described above with different concentrations of $\mathrm{ZnCl}_{2}$ (A and C), reduced glutathione (B), cysteine (D) and serine (E). (A) $\mathrm{ZnCl} 2$ with (open circles) and without (closed circles) $10 \mathrm{mM}$ of reduced glutathione; (B) $\mathrm{ZnCl}_{2}$ with different concentrations of reduced glutathione (closed circles). Control was performed in the absence of $10 \mathrm{mM} \mathrm{ZnCl}$ and reduced glutathione (open circle); (C) $\mathrm{ZnCl}_{2}$ with (open circles) and without (closed circles) $10 \mathrm{mM}$ cysteine; (D) $\mathrm{ZnCl}_{2}$ with different concentrations of cysteine (closed circles). Control was performed in the absence of $10 \mathrm{mM} \mathrm{ZnCl}_{2}$ and cysteine (open circle); (E) $\mathrm{ZnCl}_{2}$ with different concentrations of serine (open squares). Control was performed in the absence of $10 \mathrm{mM} \mathrm{ZnCl}_{2}$ and serine (open circle). Insets: Effects of different concentrations of reduced glutathione (B), cysteine (D) and serine (E) on the phosphatase activity of L. amazonensis intact cells. The values were expressed as mean percentual activities \pm standard errors of at least three independent experiments, performed in triplicate.

ing cellular oxidants (Denu and Tanner, 1998). The study of the effect of metal ions on phosphatase activity such as zinc is interesting, because it has redox properties or tight binding to sulfhydryl groups. Zinc inhibition was protected dose-dependently by coincubation with reduced glutathione and cysteine, two thiol compounds capable to bind zinc (DeChatelet et al., 1971; Giroux and Henkin, 1972; Prasad and Oberleas, 1970), whereas serine, an amino acid that does not present the thiol group, did not exert such effect (Fig. 4). This result suggests a possible role for the thiol group in the mechanism of zinc inhibition. The inhibitory effect exerted by zinc may be through the coordination of some residues in a $\mathrm{Zn}^{2+}$ binding site (Kim et al., 2000).

Specific inhibitors of protein phosphatases were used for the characterization of the ecto-phosphatase present on the surface of $L$. amazonensis. This enzyme was strongly inhibited by ammonium molybdate (Fig. 3A), classical inhibitor of acid phosphatase (Dutra et al., 1998; Ferraro et al., 2004; Jesus et al., 2002; Lemos et al., 2002), and was also sensitive to sodium orthovanadate (Fig. 3B) and bpV-PHEN (Fig. 3C) two well-known specific phosphotyrosine protein phosphatase inhibitors (Cool and Blum, 1993; Furuya et al., 1998; Posner et al., 1994), suggesting that this enzyme would be a phosphotyrosine phosphatase, as L. major (Aguirre-García et al., 2006) and other parasitic protozoa (Bakarala et al., 2000; Fernandes et al., 2003; Furuya et al., 1998; Jesus et al., 2002; Meyer-Fernandes et al., 1999). Although intact promastigotes were able to hydrolyze $P$ tyrosine, $P$-serine and $P$-threonine, only the $P$-tyrosine hydrolysis was inhibited by vanadate. Vanadate is a 


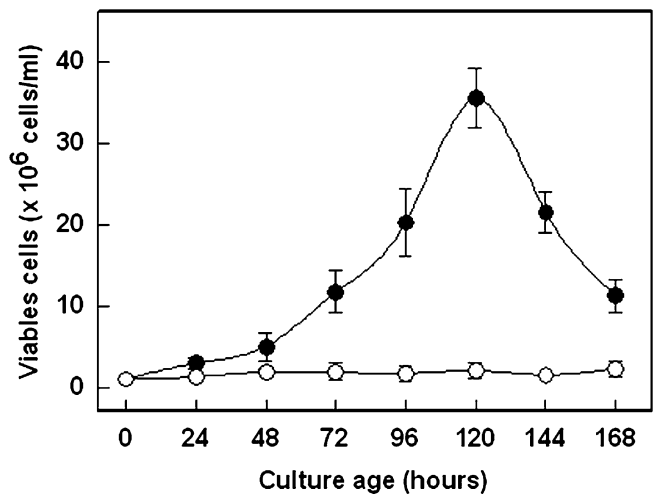

Fig. 6. Growth of L. amazonensis cultivated in Warren's medium at $22^{\circ} \mathrm{C}$ as described in Section 2 for 7 days, in the absence (closed circles) or in the presence of $1 \mathrm{mM}$ sodium orthovanadate (open circles). Values shown are means \pm standard errors of three different experiments. In the control curve (absence of vanadate) the same volume of water (solvent of vanadate solution) was added to the growth medium.

phosphate analog and is generally thought to bind as a transition state analog to the phosphoryl transfer enzymes that it inhibits, since it can easily adopt a trigonal bipyramidal structure (Huyer et al., 1997), an analysis of sodium orthovanadate inhibition showed that it behaves as a competitive inhibitor (Fig. 3B, inset; Table 1), with a $K_{\mathrm{i}}$ of $0.36 \mu \mathrm{M}$ similar to the one demonstrated in protein-tyrosine phosphatase 1B (PTP1B) (Huyer et al., 1997).

We have recently demonstrated that Fonsecaea pedrosoi, the principal causative agent of human chromoblastomycosis, uses a cell wall ecto-phosphatase, sensitive to vanadate, to interact with host epithelia and fibroblasts (Kneipp et al., 2004). Accordingly, we showed that the incubation of $L$. amazonensis promastigotes with sodium orthovanadate, increased the parasite adhesion to macrophage (Martiny et al., 1996). We have also demonstrated that L. amazonensis phosphatase activity can upregulate parasite attachment (Vannier-Santos et al., 1995) and promoted intracellular survival within macrophages (Martiny et al., 1996, 1999). The physiological role of the ecto-phosphatase in protozoa parasites is still largely unknown, but a possible involvement in the cell proliferation has also been proposed (Bernardes et al., 2000). The mechanism of inhibition promoted by ammonium molybdate and bpV-PHEN, was similar to demonstrated by sodium orthovanadate. This is not unexpected, considering the fact that like vanadate the ammonium molybdate and bpV-PHEN are phosphate structural analogs. The inorganic phosphate, product of the reaction, showed to be a competitive inhibitor (Fig. 3D, inset; Table 1), as observed in human liver acid phosphatase (Taga and Van Etten, 1982).

The ecto-phosphatase through phosphomonoester hydrolysis could supply inorganic phosphate to the parasite proliferation (Gottlieb and Dwyer, 1981; Hassan and Coombs, 1987). Accordingly, the addition of $1 \mathrm{mM}$ orthovanadate to the culture medium inhibited completely the proliferation of $L$. amazonensis. It is important to note that vanadate can affect other orthophosphate-mediated processes (Klarlund, 1985), being a potent inhibitor of cation transport P-ATPases (Cunha et al., 1992; O'Neal et al., 1979). However, vanadate is not a potent inhibitor of these processes on intact cells as the oxidation-reduction reactions which take place in the cytoplasm diminish its inhibitory effect (Cantley and Aisen, 1979).

The precise role of ecto-phosphatases is not well established, but it has been related to cell growth, providing the cell with a source of nutrients, as well as protecting the parasite by preventing the protozoan digestion in the alimentary tract of the invertebrate host (Wiese et al., 1996). Its accessibility on cell surfaces and possible involvement in essential cellular functions suggest that the ecto-phosphatase might provide a promising target for chemotherapy.

\section{Acknowledgments}

We acknowledge the excellent technical assistance of Fabiano Ferreira Esteves and Dr. Martha Sorenson (Instituto de Bioquímica Médica, Universidade Federal do Rio de Janeiro) for recommending needed changes in the English. This work was partially supported by grants from the Brazilian agencies Conselho Nacional de Desenvolvimento Científico e Tecnológico (CNPq), Coordenação de Aperfeiçoamento de Pessoal de Nível Superior (CAPES) and Fundação Carlos Chagas Filho de Amparo à Pesquisa do Estado do Rio de Janeiro (FAPERJ). The experiments performed in this work comply with the current laws of Brazil.

\section{References}

Aguirre-García, M.M., Escalona-Montaño, A.R., Bakalara, N., PérezTorres, A., Gutiérrez-Kobeh, L., Becker, I., 2006. Leishmania major: detection of membrana-bound protein tyrosine phosphate. Parasitology 5, 1-9.

Bakarala, N., Santarelli, X., Davis, C., Baltz, T., 2000. Purification, cloning and characterization of an acidic ectoprotein phosphatase differentially expressed in the infectious bloodstream form of Trypanosoma brucei. Journal of Biological Chemistry 275, 8863-8871.

Barral, A., Pedral-Sampaio, D., Grimaldi Jr., G., Momen, H., McMahonPratt, D., Ribeiro de Jesus, A., Almeida, R., Badaró, R., Barral-Netto, M., Carvalho, E.M., 1991. Leishmaniasis in Bahia, Brazil: evidence that Leishmania amazonensis produces a wide spectrum of clinical disease. American Journal of Tropical Medicine and Hygiene 44, 536-546.

Bernardes, C.F., Meyer-Fernandes, J.R., Saad-Nehme, J., Vannier-Santos, M.A., Peres-Sampaio, C.E., Vercesi, A.E., 2000. Effects of 4,4'-diisothyocyanatostilbene-2,2'-disulfonic acid on Trypanosoma cruzi proliferation and $\mathrm{Ca}^{2+}$ homeostasis. International Journal of Biochemistry and Cell Biology 32, 519-527.

Cantley, L.C., Aisen, P., 1979. The fate of cytoplasmic vanadium: implications on $(\mathrm{Na}, \mathrm{K})$-ATPase inhibition. Journal of Biological Chemistry 254, 1781-1784.

Cool, D.E., Blum, J.J., 1993. Protein tyrosine phosphatase activity in Leishmania donovani. Molecular and Cellular Biochemistry(127/128), 143-149.

Cunha, V.M., Meyer-Fernandes, J.R., Noel, F., 1992. A $\left(\mathrm{Ca}^{2+}-\mathrm{Mg}^{2+}\right)$ ATPase from Schistosoma mansoni is coupled to an active transport of calcium. Molecular and Biochemical Parasitology 52, 167-173.

DeChatelet, L.R., Cooper, M.R., McCall, C.E., 1971. Studies on leukocyte phosphatase. III. Inhibition of leukocyte acid phosphatase by zinc. Clinical Chemistry 17, 1176-1179. 
Denu, J.M., Tanner, K.G., 1998. Specific and reversible inactivation of protein tyrosine phosphatase by hydrogen peroxide: evidence for a sulfenic acid intermediate and implications for redox regulation. Biochemistry 37, 5633-5642.

Desjeux, P., 2004. Leishmaniasis: current situation and new perspectives. Comparative Immunology, Microbiology and Infectious Diseases 27, 305-318.

Dutra, P.M.L., Rodrigues, C.O., Jesus, J.B., Lopes, A.H.C.S., Souto-Padrón, T., Meyer-Fernandes, J.R., 1998. A novel Ecto-phosphatase activity of Herpetomonas muscarum muscarum inhibited by plateletactivation factor. Biochemical and Biophysical Research Communications 253, 164-169.

Fernandes, E., Meyer-Fernandes, J.R., Silva-Neto, M.A., Vercesi, A.E., 1997. Trypanosoma brucei: ecto-phosphatase activity present on the surface of intact procyclic forms. Zeitschrift für Natuforschung 52c, 351-358.

Fernandes, E.C., Granjeiro, J.M., Taga, E.M., Meyer-Fernandes, J.R., Aoyama, H., 2003. Phosphatase activity characterization on the surface of intact bloodstream forms of Trypanosoma brucei. FEMS Microbiology Letters 220, 197-206.

Ferraro, R.B., Souza, J.L., Cunha, R.D.C., Meyer-Fernandes, J.R., 2004. Characterization of an ecto-phosphatase activity in malpighian tubules of hematophagous bug Rhodnius prolixus. Archives of Insect Biochemistry and Physiology 57, 40-49.

Fischer, E.H., Charbonneau, H., Tonks, N.K., 1991. Protein tyrosine phosphatases: a diverse family of intracellular and transmembrane enzymes. Science 253, 401-406.

Fiske, C.H., Subbarow, J.W., 1925. The colorimetric determination of phosphorous. Journal of Biological Chemistry 66, 375-392.

Furuya, T., Zhong, L., Meyer-Fernandes, J.R., Hong-Gang, L., Moreno, S.N.J., Docampo, R., 1998. Ecto-protein tyrosine phosphatase activity in Trypanosoma cruzi infective stages. Molecular and Biochemical Parasitology 92, 339-348.

Giroux, E., Henkin, R., 1972. Competition for zinc among serum albumin and amino acids. Biochimica et Biophysica Acta 273, 64-72.

Glew, R.H., Czuczam, M.F., Berens, R.L., Pope, M.T., Katsoulis, D.E., 1982. Partial purification and characterization of particle acid phosphatase of Leishmania donovani promastigote. Comparative Biochemistry Physiology 72, 581-590.

Gottlieb, M., Dwyer, D.M., 1981. Protozoan parasite of humans: surface membrane with externally disposed acid phosphatase. Science 212, 939-941.

Grimaldi Jr., G., Tesh, R.B., 1993. Leishmaniases of the new world: current concepts and implications for future research. Clinical Microbiology Reviews 6, 230-250.

Hassan, H.F., Coombs, G.H., 1987. Phosphomonoesterase of Leishmania mexicana and other flagellates. Molecular and Biochemical Parasitology 23, 2852-2896.

Hunter, T., 1995. Protein kinases and phosphatases: the yin and yang of protein phosphorylation and signaling. Cell 80, 225-236.

Huyer, G., Liu, S., Kelly, J., Moffat, J., Payette, P., Kennedy, B., Tsaprailis, G., Gresser, M.J., Ramachandran, C., 1997. Mechanism of inhibition of protein-tyrosine phosphatase by vanadate and pervanadate. Journal of Biological Chemistry 272, 843-851.

Jesus, J.B., Podlyska, T.M., Lopes, A.H.C.S., Vannier-Santos, M.A., MeyerFernandes, J.R., 2002. Characterization of an ecto-phosphatase activity in the human parasite Trichomonas vaginalis. Parasitology Research 88, 991-997.

Katakura, K., Kobayashi, A., 1988. Acid phosphatase activity of virulent and avirulent clones of Leishmania donovani promastigotes. Infection Immunity 56, 2856-2860.

Klarlund, J., 1985. Transformation of cells by an inhibitor of phosphatases acting on phosphotyrosine proteins. Cell 41, 707-717.

Kneipp, L.F., Rodrigues, M.L., Holandino, C., Esteves, F.F., Alviano, C.S., Travassos, L.R., Meyer-Fernandes, J.R., 2004. Ecto-phosphatase activity in conidial forms of Fonsecaea pedrosoi is modulated by exogenous phosphate and mediates fungal adhesion to epithelial cells. Microbiology $150,3355-3362$.
Kim, J.H., Cho, H., Ryu, S.E., Choi, M.U., 2000. Effects of metal ions on the activity of protein tyrosine phosphatase VHR: highly potent and reversible oxidative inactivation by $\mathrm{Cu}^{2+}$ Ion. Archives of Biochemistry and Biophysics 382, 72-80.

Lau, K.H.W., Farley, J.R., Baylink, D.J., 1989. Phosphotyrosyl protein phosphatases. Biochemical Journal 257, 23-36.

Lemos, A.P., Souza, A.L.F., Pinheiro, A.A.S., Berrêdo-Pinho, M., MeyerFernandes, J.R., 2002. Ecto-phosphatase activity on the cell surface of Crithidia deanei. Zeitschrift für Natuforschung 57c, 500-505.

Martiny, A., Vannier-Santos, M.A., Borges, V.M., Meyer-Fernandes, J.R., Assreuy, J., Cunha e Silva, N.L., de Souza, W., 1996. Leishmaniainduced tyrosine phosphorylation in the host macrophage and its implication to infection. European Journal of Cell Biology 71, 206-215.

Martiny, A., Meyer-Fernandes, J.R., de Souza, W., Vannier-Santos, M.A., 1999. Altered tyrosine phosphorylation of ERK1 MAP kinase and other macrophage molecules caused by Leishmania amastigotes. Molecular and Biochemical Parasitology 102, 1-12.

Menz, B., Winter, G., Ilg, T., Lottspeich, F., Overath, P., 1991. Purification and characterization of a membrane-bound acid phosphatase of Leishmania mexicana. Molecular and Biochemical Parasitology 47, 101-108.

Meyer-Fernandes, J.R., Dutra, P.M.L., Rodrigues, C.O., Saad-Nehme, J., Lopes, A.H.C.S., 1997. Mg-dependent Ecto-ATPase activity in Leishmania tropica. Archives of Biochemistry and Biophysics 341, 40-46.

Meyer-Fernandes, J.R., Silva-Neto, M.A., Soares, M.S., Fernandes, E., Vercesi, A.E., Oliveira, M.M., 1999. Ecto-phosphatase activities on the cell surface of the amastigote forms of Trypanosoma cruzi. Zeitschrift für Natuforschung 54c, 977-984.

O'Neal, S.G., Rhoads, D.B., Racker, E., 1979. Vanadate inhibition of sarcoplasmic reticulum $\mathrm{Ca}^{2+}$-ATPase and other ATPases. Biochemical and Biophysical Research Communications 89, 845-850.

Parsons, M., Valentine, M., Carter, V., 1993. Protein kinases in divergent eukaryotes: Identification of protein kinase activities regulated during trypanosome development. Proceedings of the National Academy of Science of United States of America 90, 2656-2660.

Posner, B.I., Faure, R., Burgess, J.W., Bevan, A.P., Lachance, D., ZhnagSun, G., Fantus, I.G., Ng, J.B., Hall, D.A., Lum, B.S., Shaver, A., 1994. Peroxovanadium compounds a new class of potent phosphotyrosine phosphatase inhibitors which are insulin mimetics. Journal of Biological Chemistry 269, 4596-4604.

Prasad, A., Oberleas, D., 1970. Binding of zinc to amino acids and serum proteins in vitro. Journal of Laboratory and Clinical Medicine 76, 416-425.

Remaley, A.T., Das, S., Campbell, P.I., LaRocca, G.M., Pope, M.T., Glew, R.H., 1985. Characterization of Leishmania donovani acid phosphatases. Journal of Biological Chemistry 260, 880-886.

Saha, A.K., Das, S., Glew, R.H., Gottlieb, M., 1985. Resistance of leishmanial phosphatases to inactivation by oxygen metabolites. Journal of Clinical Microbiology 22, 329-332.

Singla, N., Khuller, G.K., Vinayak, V.K., 1992. Acid phosphatase activity of promastigotes of Leishmania donovani: a marker of virulence. FEMS Microbiology Letters 94, 221-226.

Taga, E.M., Van Etten, R.L., 1982. Human liver acid phosphatases: purification and properties of a low-molecular-weight isoenzyme. Archives of Biochemistry and Biophysics 214, 505-515.

Vannier-Santos, M.A., Martiny, A., Meyer-Fernandes, J.R., de Souza, W., 1995. Leishmanial protein kinase C modulates host cell infection via secreted acid phosphatase. European Journal of Cell Biology 67, 112-119.

Vannier-Santos, M.A., Martiny, A., de Souza, W., 2002. Cell biology of Leishmania spp.: invading and evading. Current Pharmaceutical Design 8, 297-318.

Warren, L.G., 1960. Metabolism of Schizotrypanum cruzi chagas. I. Effect of culture age and substrate concentration on respiratory rate. The Journal of Parasitology 46, 529-539.

Wiese, M., Berger, O., Stierhof, Y.D., Wolfram, M., Fuchs, M., Overath, P., 1996. Gene cloning and cellular localization of a membrane-bound acid phosphatase of Leishmania mexicana. Molecular and Biochemical Parasitology 82, 153-165. 